\section{Regional variation in antipsychotic polypharmacy for schizophrenia}

\section{QUESTION}

Question: Are there regional differences in the attitudes of nurses and physicians to antipsychotic polypharmacy (APP) and the use of clinical guidelines?

Population: The prevalence of APP in 2004 in different municipalities in Denmark was determined using records from the Danish National Board of Health and the Danish Medicines Agency. The number of outpatients with an ICD-10 (International Statistical Classification of Diseases and Related Health Problems 10th Revision) diagnosis of schizophrenia spectrum disorder who were treated with more than one antipsychotic (as defined by the filling of prescriptions for more than one antipsychotic within 30 days during 2004) were compared with the total number of antipsychotic-treated patients with schizophrenia spectrum disorder to determine the APP fraction. Two municipalities with a mean APP fraction above the national average of $48.5 \%$ and two with a mean APP below this average were selected. The regions had comparable need for mental health services (as determined by socioeconomic predictors) and similar organisation of psychiatric services. The nurses and physicians in one of the main psychiatric departments and outpatient clinics in each region served as the target population.

Setting: Four municipalities in Denmark selected from all 98 municipalities; two with lower APP prescribing than the national average (Frederiksberg and Odense) and two with higher (Esbjerg and Viborg).

Assessment: Questionnaires were distributed to all physicians and nurses in the psychiatric departments and outpatients clinics in the selected municipalities. Additional data were collected from administrative records about the treatment setting in each department such as the number of beds, research activity, number of academic staff, availability of a treatment guideline, how up to date this was and what initiatives were in place to encourage adherence to it. These variables were compared between the municipalities with below average polypharmacy prescribing and those with above average. Categorical variables were compared using $\chi^{2}$ tests and continuous variables using Wilcoxon tests. A correction for multiple testing was applied, and OR with $98 \%$ CI calculated for questions that were significantly different between above and below average APP fraction regions.
Outcomes: Nurse and physician knowledge and attitudes regarding APP and guideline use; treatment setting variables including availability of guidelines.

\section{METHODS}

Design: Cross-sectional study.

\section{MAIN RESULTS}

The difference in APP fractions across the regions was not related to differences in disease severity. This was determined by adjusting for disease severity as measured using patient Global Assessment of Functioning scores and substance abuse data. Of 347 participants, 309 (89\%) returned their questionnaires. This included 78 physicians and 230 nurses responded across the four municipalities. None of the nurses was authorised to prescribe medication. Compared with high APP areas, physicians in low APP areas had improved knowledge of treatment guidelines ( $87 \%$ vs $65 \%, p=0.02)$; believed guidelines were more important than personal experience $13 \%$ vs $38 \%$, $\mathrm{p}=0.01)$; were offered local education sessions more frequently (76\% vs 9\%, p<0.0001) and were more engaged in recent scientific activity (41\% vs $13 \%, \mathrm{p}=0.01)$. Compared with high APP areas, nurses in low APP areas had improved knowledge of treatment guidelines ( $74 \%$ vs $58 \%$, p=0.01); were less likely to think that polypharmacy increased antipsychotic effect $(19 \%$ vs $38 \%, p=0.001)$; were less likely to have education offered at least once monthly ( $34 \%$ vs $50 \%, \mathrm{p}=0.01$ ); perceived they had sufficient time for each patient $(57 \%$ vs $37 \%, \mathrm{p}=0.003)$ and were less likely to believe their workload was too high $(26 \%$ vs $44 \%, \mathrm{p}=0.01$ ).

\section{CONCLUSIONS}

There is an association between APP and nurse time pressure and request for further medication and between physician's medication knowledge and disuse of algorithms.

\section{ABSTRACTED FROM}

Baandrup L, Allerup P, Nordentoft M, et al. Exploring regional variation in antipsychotic coprescribing practice: a Danish questionnaire survey. J Clin Psychiatry 2010;71:1457-64.

Correspondence to: Lone Baandrup, Center for Neuropsychiatric Schizophrenia Research, Copenhagen University Hospital, Psychiatric Center Glostrup, Nordre Ringvej 29-67, DK-2600 Glostrup, Denmark; lone.baandrup@cnsr.dk

Sources of funding: National Board of Health in Denmark and the Worzner Foundation.

References are available online only. To view please visit the journal online at http://ebmj.bmj.com
$\mathrm{M}$ ost schizophrenia treatment guidelines recommend that antipsychotic combinations only be considered when sequential monotherapy trials including clozapine have been unsuccessful. ' However, we know that excessive antipsychotic polytherapy (APT) rates have been reported despite the lack of evidence for improved efficacy compared with antipsychotic monotherapy.

Baandrup and colleagues undertook a survey to investigate factors related to variations in APT prescribing rates in four regions of Denmark (two pairs in a low and high APT service setting). A high response rate of $89 \%$ was achieved and found that working in a service setting with low APT use was associated with raised knowledge/ awareness of treatment guidelines for physicians and nurses. For physicians, working in a low-prevalence APT setting was also associated with stronger beliefs in guidelines than in personal experience, more engagement in research activity and increased availability of educational sessions. Unexpectedly, nurses working in low-prevalence services had access to fewer educational activities. More nurses in low-prevalence APT settings felt less burdened by their workload, had sufficient time for each patient and were less likely to believe that APT was useful in increasing antipsychotic effect.

This study supports the findings of others with associations between APT and beliefs about the relevance of guidelines, work pressure and teaching environments. A limitation acknowledged by the authors was the multiple testing undertaken and the potential for type 1 error in this study, with up to 20 factors examined for an association with APT. Further investigation using a multivariate approach with a larger sample may help to untangle some of the interactions between these factors.

Nevertheless, the practical question of how to close the gap between evidence and practice still remains a dilemma. The authors recommend a service environment with easy access to guidelines, frequent academic activities and an unruffled atmosphere; however, the head of all four service settings in the study reported having a local guideline which had been disseminated by a range of activities to ensure implementation, the work pressure in the settings was similar and only one service had an academic staff component. We need to identify effective strategies to raise knowledge and awareness of guideline recommendations and to ensure that these recommendations translate into routine clinical practice.

\section{Amanda J Wheeler}

School of Human Services, Griffith Health, Griffith University, Brisbane, Queensland, Australia

Competing interests None. 

polypharmacy for schizophrenia

Evid Based Mental Health 2011 14: 68 originally published online June 10,2011

doi: 10.1136/ebmh1174

Updated information and services can be found at:

http://ebmh.bmj.com/content/14/3/68.full.html

\begin{tabular}{cl}
\hline References & $\begin{array}{l}\text { These include: } \\
\text { This article cites 1 articles } \\
\text { http://ebmh.bmj.com/content/14/3/68.full.html\#ref-list-1 }\end{array}$ \\
$\begin{array}{c}\text { Email alerting } \\
\text { service }\end{array}$ & $\begin{array}{l}\text { Receive free email alerts when new articles cite this article. Sign up in } \\
\text { the box at the top right corner of the online article. }\end{array}$ \\
Topic & Articles on similar topics can be found in the following collections \\
& $\begin{array}{l}\text { Drugs: psychiatry (266 articles) } \\
\text { Guidelines (19 articles) } \\
\text { Schizophrenia spectrum (340 articles) } \\
\text { Substance dependence (360 articles) } \\
\text { Epidemiologic studies (461 articles) } \\
\text { Epidemiology (1251 articles) } \\
\text { Neurology (894 articles) } \\
\text { Nursing (25 articles) }\end{array}$ \\
\hline
\end{tabular}

Notes

To request permissions go to:

http://group.bmj.com/group/rights-licensing/permissions

To order reprints go to:

http://journals.bmj.com/cgi/reprintform

To subscribe to BMJ go to:

http://group.bmj.com/subscribe/ 